Gut, 1986, 27, 698-704

\title{
Incidence of methanogenic bacteria in a sigmoidoscopy population: an association of methanogenic bacteria and diverticulosis
}

\author{
G A WEAVER, J A KRAUSE, T L MILLER, AND M J WOLIN
}

From the Department of Medicine, The Mary Imogene Bassett Hospital (affiliated with Columbia University), Cooperstown, New York, and Wadsworth Center for Laboratories and Research, New York State

Department of Health, Albany, New York, USA.

SUMMARY This study determined the incidence and concentration of methane-producing bacteria in tap water enema samples of 130 individuals taken before sigmoidoscopy. The number of subjects classified in five major colonic groups were as follows: normal colon 36 , diverticulosis 57 , inflammatory bowel disease 11 , colon polyps 34 , and colon cancer 11 . Some patients were placed in more than one category. Ninety four of the subjects or $72 \%$ had methanogenic bacteria ranging in concentration from 6 to about $3 \times 10^{10} / \mathrm{g}$ dry weight of faeces. The predominant methanogen in all groups was Methanobrevibacter smithii. Chi-square analysis showed that the incidence of methanogens in concentrations of $10^{7} / \mathrm{g}$ dry weight of faeces or greater in patients with diverticulosis $(58 \%)$ was significantly greater than in normal patients $(25 \%)$. High methanogen concentrations are associated with excretion of methane in the breath.

Studies by Bond et al $^{1}$ showed that methane in man is produced by bacteria in the colon and indicated that most methane production occurs in the left colon. Methane is not metabolised further in man. It was estimated ${ }^{1}$ that $20 \%$ of that produced is excreted through the lungs and that the remainder is passed as flatus. Miller and Wolin ${ }^{2}{ }^{3}$ showed that the predominant methane producing organism in humans is Methanobrevibacter smithii. It produces methane by using hydrogen to reduce carbon dioxide. This organism remains at about the same concentration in the faeces of individuals studied over a period of $10-13$ months. ${ }^{4}$

Thirty to $61 \%$ of adults excrete methane in the breath. $^{1-9}$ Breath methane is established in individuals between the ages of two and $10 .{ }^{1}$ Unlike breath hydrogen, breath methane does not usually increase when methane producers are given a non-absorbed carbohydrate. ${ }^{10}$ Breath methane does, however, increase in producers with high endogenous methane production after they are given a large dose of a non-absorbed carbohydrate. ${ }^{6} \$ 1112$

Address for correspondence: G A Weaver. The Mary Imogene Bassett Hospital, Cooperstown. New York 13326. USA

Received for publication 9 September 1985.
Haines et al ${ }^{13}$ noted an increased incidence of the presence of methane in the breath of patients with colon cancer. More recently, Pique et al ${ }^{8}$ have also shown this association, although work by Karlin et $a^{14}$ did not show this association. Other studies have reported the incidence of methane in the breath, but there has been no previous study to compare the incidence and types of methanogenic bacteria in normal subjects with those with large bowel disorders, nor has an attempt been made to correlate breath levels of hydrogen and methane with the number of methanogenic organisms per gram dry weight of stool (gdw). In this study, the incidence, concentration, and types of methanogenic organisms as well as concentrations of total viable anaerobic bacteria were determined in a population that presented for sigmoidoscopy. Breath levels of hydrogen, methane, and carbon dioxide were determined in 48 consecutive patients who agreed to a breath test.

\section{Methods}

PATIENTS

Patients presenting for flexible sigmoidoscopy on Thursday afternoons, regardless of the reason for 
referral, were asked to donate enema and breath samples. Patients were referred to the clinic for a variety of reasons; a change in bowel habits, rectal bleeding, diarrhoea, follow up of resected polyps, follow up of colon cancer, and routine examinations. Samples were obtained only after informed consent. This study was reviewed and approved by the review board for human subjects of The Mary Imogene Bassett Hospital, July 1981.

Patients were placed in diagnostic categories based on historical information, a questionnaire filled out by the patients before sigmoidoscopy, available previous or subsequent barium radiographs of the colon and the findings at sigmoidoscopy. Patients were classified by the following criteria: (normal colon) between three formed motions daily to one formed motion every three days plus a normal flexible sigmoidoscopy (an abnormal barium enema excluded patients from this group); (diverticulosis) the presence of diverticula at sigmoidoscopy or on barium enema (it is possible that a few individuals in the normal group who did not have barium enema examinations may have had undiagnosed diverticulosis); (inflammatory bowel disease) patients with endoscopic findings consistent with Crohn's disease or ulcerative colitis along with biopsy evidence of significant inflammation or abnormality of the ileum on barium examination; (colon polyps) biopsy proven tubular, villo tubular, or villous polyps (adenomatous or villous adenomas) past or present; (colon cancer) patients who had previously had a colon cancer resected or who were found to have carcinoma at the time of flexible sigmoidoscopy. This includes patients with carcinoma in situ or invasive colon cancer in polyps.

STOOL COLLECTION AND ANALYSIS

Patients presented without any previous bowel preparation. Flexible sigmoidoscopy was carried out between 1300 and 1600 hours. Most patients had omitted their noon meal before the exam and specimen collection. After a tap water enema, a specimen was voided into a commode lined with a nylon bag. The sample was kneaded into a homogenous suspension. Approximately $75 \mathrm{ml}$ aliquots were transferred to a $100 \mathrm{ml}$ serum bottle. After inserting a butyl rubber stopper and sealing with an aluminium seal, the bottles were gassed for two minutes with nitrogen with hypodermic needles used for the entry and exit of the gas. These aliquots were kept at $4^{\circ} \mathrm{C}$ and processed within 24 hours of collection. Initial studies showed that there was no significant change in the concentrations of methanogens or total anaerobic bacteria between samples processed immediately and in those processed after storage at $4^{\circ} \mathrm{C}$ for 24 hours. Samples containing high concentrations of solids was transferred to a sterile plastic bag, gassed with carbon dioxide and mixed in a Stomacher Lab-Blender (Tekmar Co, Cincinnati, $\mathrm{OH})$ for two minutes. Samples with low concentrations were mixed in the serum bottle with a vortex mixer.

The serum bottle modification of the Hungate anaerobic technique for the enumeration and cultivation of bacteria ${ }^{15}$ was used throughout the study. The media used for enumeration of total viable anaerobic and methanogenic bacteria is described by Miller and Wolin. ${ }^{3} \mathrm{~A} 10^{-1}$ dilution was prepared in anaerobic dilution ${ }^{16}$ solution in a sterile serum bottle, which was gassed with $100 \%$ carbon dioxide, stoppered and crimped. For total anaerobic counts, 0.1 or $0.5 \mathrm{ml}$ of each appropriate dilution was inoculated in duplicate in roll tubes containing a complex medium with $10 \%$ rumen fluid and agar and a $100 \%$ carbon dioxide gas phase. Methanogens were enumerated in duplicate in the same medium with the addition of cephalothin, clindamycin, and an $80 \%$ hydrogen: $20 \%$ carbon dioxide gas phase. All incubations were at $37^{\circ} \mathrm{C}$. Roll tube colonies were counted at $14 \mathrm{~d}$ and portions of the headspace of antibiotic containing roll tubes were analysed for methane. ${ }^{3}$ Duplicate portions $(5-15 \mathrm{ml})$ of enema samples were weighed, dried in an oven at $110^{\circ} \mathrm{C}$ for 24-48 h, transferred to a desiccator containing Drierite and dried to constant weight. For enrichment of methanogens, the serum bottle containing the $10^{-1}$ dilution was regassed and pressurised to two atmospheres $(202.6 \mathrm{kPa})$ with $80 \%$ hydrogen- $20 \%$ carbon dioxide and incubated for $14 \mathrm{~d}$ and then analysed for methane.

\section{ISOLATION AND CHARACTERISATION OF \\ METHANOGENIC BACTERIA}

Methanogenic bacteria were isolated from the most dilute inoculum of antibiotic-containing roll tubes that had headspace methane. Isolation and physiologic and immunologic characterisation were according to previously described procedures. ${ }^{2.3}$ Epifluorescent microscopy procedures were used to detect the natural fluorescence of methanogenic bacteria in faecal samples and in pure cultures. ${ }^{2}$

\section{BREATH COLLECTION}

Breath samples were obtained by using a modified Priestly-Haldane ${ }^{17}$ tube $167 \mathrm{~cm}$ long with an inside diameter of $1.27 \mathrm{~cm}$. A one way valve placed at the mouth end prevented inhalation through the tube. A $30 \mathrm{cc}$ syringe fitted with a Teflon gas valve immediately beyond the one way valve was used to aspirate the breath sample at the end of exhalation. Breath samples were analysed within three hours for hydrogen using a Gow-Mac Series 550P thermal 
conductivity gas chromatograph (Bound Brook, NJ) with a $1.8 \mathrm{~m}$ by $1 \mathrm{~cm}$ stainless steel column packed with 60/80 mesh silica gel (Alltech Associates, Inc., Deerfield, IL 60015). The carrier gas was argon at a flow rate of $20 \mathrm{ml} / \mathrm{min}$. The operating conditions were as follows: (1) injector and column temperature $=80^{\circ} \mathrm{C}$; (2) detector temperature $=$ $30^{\circ} \mathrm{C}$; and (3) bridge current $=90$ milliamps. A $2 \mathrm{ml}$ sample was injected using a conventional plastic syringe fitted with a mininert Teflon valve and a 25 gauge needle. Three certified standards (AIR Products and Chemicals, Inc, Tamaqua, PA) containing $0.45,2.33$, and $4.46 \mu \mathrm{mol} / \mathrm{l}$ of hydrogen, and $0.0092,0.0227$, and $0.0318 \mathrm{~mol} / \mathrm{l}$ of carbon dioxide, respectively, were used to establish a linear regression.

A model 3390A Hewlett-Packard integrator (Palo Alto, CA) was used to measure peak area for hydrogen and carbon dioxide. Hydrogen breath samples were initially corrected for the deviation of observed carbon dioxide concentrations from normal alveolar carbon dioxide concentrations. ${ }^{18}$ These corrections made little difference in overall results, however, so only uncorrected hydrogen values are reported.

Breath methane concentrations were measured using a Perkin-Elmer gas chromatograph (Norwalk, CT) with a flame ionization detector. A $1.8 \mathrm{~m}$ by $1 \mathrm{~cm}$ stainless steel column packed with molecular sieve 5A-60/80 mesh (Alltech Associates, Deerfield, IL) was used. The carrier gas was nitrogen with a flow rate of $70 \mathrm{ml} / \mathrm{min}$. Operating conditions were as follows: (1) detector and injector temperature $=175^{\circ} \mathrm{C} ;(2)$ oven temperature $=150^{\circ} \mathrm{C}$. A $1 \mathrm{ml}$ sample was injected using a conventional plastic syringe fitted with a $25 \mathrm{~g}$ needle. Peak height was measured using a Gow-Mac model 70-700 chart recorder (Bound Brook, $\mathrm{NJ}$ ). As with hydrogen and carbon dioxide, three certified standards (AIR
Products and Chemicals, Inc, Tamaqua, PA 18252) containing $0 \cdot 25,2 \cdot 5$, and $4.46 \mu \mathrm{mol} / \mathrm{l}$ of methane were used to establish a linear regression. Methane concentrations were determined by peak height based on a calibration curve obtained from the standards.

Room air methane concentrations in the enema room where breath samples were collected were consistently between 0.18 and $0.22 \mu \mathrm{mol} / \mathrm{l}$ with an occasional value between 0.22 and $0.27 \mu \mathrm{mol} / \mathrm{l}$. Room air in the gas chromatography laboratory was consistently between 0.09 to $0.18 \mu \mathrm{mol} / \mathrm{l}$. A background level of $0.27 \mu \mathrm{mol} / \mathrm{l}$ was subtracted from the breath methane levels reported here.

\section{Results}

Methanogenic bacteria were detected in $72 \%$ of the total population with no significant differences between any of the colonic classification groups. There was, however, a significant difference in the percentage of subjects with high methanogen concentrations in the diverticulosis group as compared with other subjects and normal subjects. There was also a significant difference in the means of the log concentrations of methanogens between diverticulosis subjects and others and normals (Table 1). In the normal group, $25 \%$ of the subjects had concentrations of $10^{7}$ or more methanogens/gdw, whereas $58 \%$ of the diverticulosis group had $10^{7}$ or more methanogens/gdw. Using $\chi^{2}$ analysis, this difference was significant with a $p$ value of $0 \cdot 01$. Comparing the incidence of methanogens in concentrations of $10^{7}$ or more per gdw in all subjects without diverticulosis $(29 \%)$ and those with diverticulosis (58\%) using $\chi^{2}$ analysis, the difference is significant with a $p$ value of $0 \cdot 001$. No significant difference in the percentage of subjects with concentrations of methanogens of $10^{7} / \mathrm{gdw}$ or greater was found between any of the

Table 1 Concentrations of bacteria by subject category

\begin{tabular}{|c|c|c|c|}
\hline \multirow{3}{*}{ Population category } & \multirow{3}{*}{ Age $\pm S D$} & \multicolumn{2}{|c|}{ Concentrations of bacteria $\left(\log _{\|} / g d w\right)^{*}$} \\
\hline & & Methanogens & Total anaerobes \\
\hline & & $-\ldots$ & $\ldots \ldots$ \\
\hline Normal $(36) \dagger$ & $54 \pm 12$ & $3.52 \pm 3.90(1.44) \div$ & $11 \cdot 52 \pm() \cdot 40$ \\
\hline Diverticulosis (57) & $63 \pm 12$ & $5.66 \pm 3.95(7.23) \div \$$ & $11 \cdot 46 \pm 0 \cdot 43$ \\
\hline Polyps (34) & $62 \pm 13$ & $4.67 \pm 3.98(5.18)$ & $11 \cdot 37 \pm 0 \cdot 35$ \\
\hline Inflammatory bowel discasc (11) & $41 \pm 18$ & $2 \cdot 89 \pm 3 \cdot 55(1.36)$ & $11 \cdot 15 \pm 0 \cdot 75$ \\
\hline Colon cancer (11) & $67 \pm 8$ & $3 \cdot 68 \pm 4 \cdot(05(1 \cdot 33)$ & $11 \cdot 31 \pm 0 \cdot 29$ \\
\hline All subjects less diverticulosis subjects (73) & $54 \pm 15$ & $3.60 \pm 3.98(1.46) \$$ & $11 \cdot 40 \pm 0 \cdot 50$ \\
\hline All subjects $(130)$ & $58 \pm 15$ & $4 \cdot 50 \pm 4 \cdot() 8(3 \cdot 46)$ & $11 \cdot 42 \pm 0 \cdot 47$ \\
\hline
\end{tabular}

* Means \pm standard deviation (median).

$\leftarrow$ Number of subjects.

\$Mcans of $\log _{10}$ concentrations are significantly different by the $t$ test: $p=() \cdot() 1$.

$\$$ Means of $\log _{10}$ concentrations are significantly different by the $t$ test; $p=(0 .(0) 4$. 


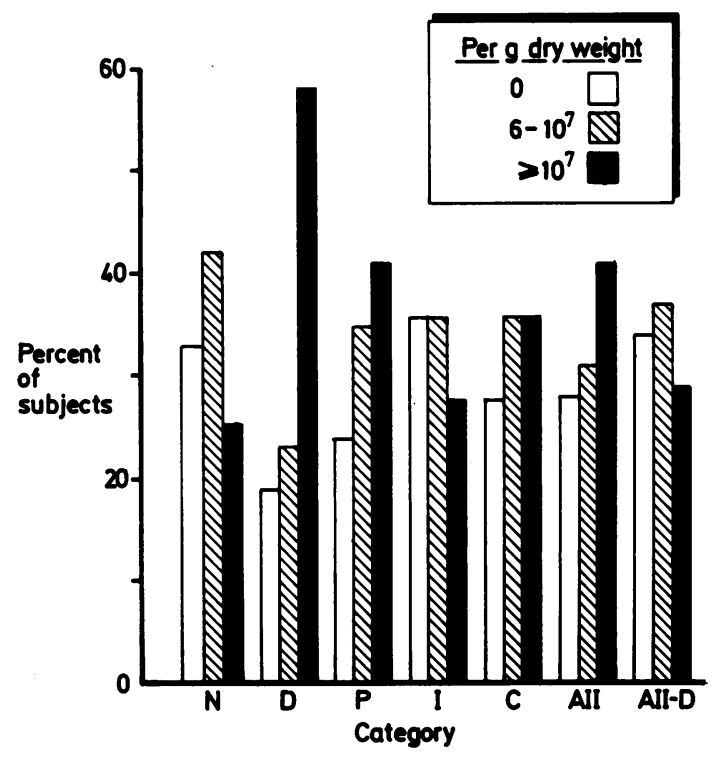

Figure Distribution of methanogen concentrations. Categories are $N$, normal; $D$, diverticulosis; $P$, polyps; $I$, inflammatory bowel disease; $C$, colon cancer; $A L L$, all subjects in the study; and ALL-D, all subjects less the diverticulosis group. Number of individuals in each concentration range is given at the top of the bar.

other groups. The numbers and per cent of subjects in three concentration ranges of 0,6 to $<10^{7}$, and $\geqq 10^{7}$ are shown in the Figure.

When all subjects were considered together, there was a trend for older patients to have higher methanogen concentrations (Table 2). Of those over $60,50 \%$ had $10^{7}$ or more methanogens/gdw while $33 \%$ of those under age 60 had $10^{7}$ or more methanogens/gdw. In the normal group, however, $22 \%$ of those 60 and over had $10^{7}$ or more methanogens/gdw and those under $60,27 \%$. There- fore, there is no apparent age related difference for the normal group. For the diverticulosis group, $61 \%$ age 60 and over and $54 \%$ / of those under 60 had $10^{7}$ or more methanogens/gdw. Comparing subjects with normal colons age 60 and over with the same age group with diverticulosis, the percentages with 107 or more methanogens/gdw of stool are $22 \%$ and $61 \%$, respectively. Using $\chi^{2}$ analysis, these values are significantly different with a $p$ value of $0 \cdot 01$. Of the diverticulosis group, $61 \%$ were over 60 whereas $45 \%$ of all other subjects were over 60 .

Some subjects had had barium enema examinations within the preceeding four weeks of stool collection. There were no significant differences in total anaerobic bacteria or methanogen concentrations between subjects with barium enema examinations in the preceeding four weeks compared with those without preceeding barium enemas in the normal group or the diverticulosis group.

Only six subjects had antibiotics in the preceeding two months. None in the normal group and two in the diverticulosis group. Methanogen concentrations in these later two subjects were lower than the mean for the entire diverticulosis group.

It was possible that different species of methanogens might be associated with one or another of the colon classification groups. Epifluorescence microscopic examination of samples containing methanogens and observations of colonial morphology in the antibiotic containing medium, however, gave no indication of a species that was morphologically different from $M$ smithii. In addition, pure colonies of methanogens from the highest dilutions of representative samples from 24 subjects representing each group were isolated and characterised by morphological, physiological, and immunological methods. $^{23}$ The number of separate isolations in each category were normal seven, diverticulosis seven, inflammatory bowel four, polyps three, cancer and diverticulosis one, polyps and diverti-

Table 2 Bacterial concentration by age and subject category

\begin{tabular}{|c|c|c|c|}
\hline \multirow[b]{2}{*}{ Population category } & \multirow[b]{2}{*}{$A g e \pm S D$} & \multicolumn{2}{|c|}{ Concentrations of bacteria $\left(\log _{1} d g d w\right)^{*}$} \\
\hline & & Methanogens & Total anaerobes \\
\hline Normal $\geqq 60(14) \dagger$ & $66 \pm 5$ & $4.07 \pm 3.86(3.25)$ & $11 \cdot 66 \pm 0 \cdot 39$ \\
\hline Normal $<60(22)$ & $47 \pm 9$ & $3 \cdot 17 \pm 3.97(1 \cdot 26)$ & $11 \cdot 43 \pm 0 \cdot 39$ \\
\hline Diverticulosis $\geqq 60$ (33) & $72 \pm 8$ & $6 \cdot 12 \pm 3.95(8 \cdot 25)$ & $11 \cdot 56 \pm 0 \cdot 33$ \\
\hline Diverticulosis $<60(24)$ & $51 \pm 6$ & $5.03 \pm 3.95(7.06)$ & $11 \cdot 32 \pm 0 \cdot 50$ \\
\hline All subjects less diverticulosis $<60$ (40) & $44 \pm 12$ & $2 \cdot 76 \pm 3.60(1.36)$ & $11 \cdot 34 \pm 0 \cdot 57$ \\
\hline All $\geqq 60(66)$ & $70 \pm 7$ & $5 \cdot 37 \pm 4 \cdot 12(6 \cdot 83)$ & $11 \cdot 52 \pm 0 \cdot 35$ \\
\hline All $<60(64)$ & $47 \pm 11$ & $3.61 \pm 3.60(1.49)$ & $11 \cdot 33 \pm 0 \cdot 54$ \\
\hline
\end{tabular}

*Means \pm standard deviation (median).

$\dagger$ (Number of subjects). 
Table 3 Comparison of breath gas concentrations with faecal methanogen concentrations

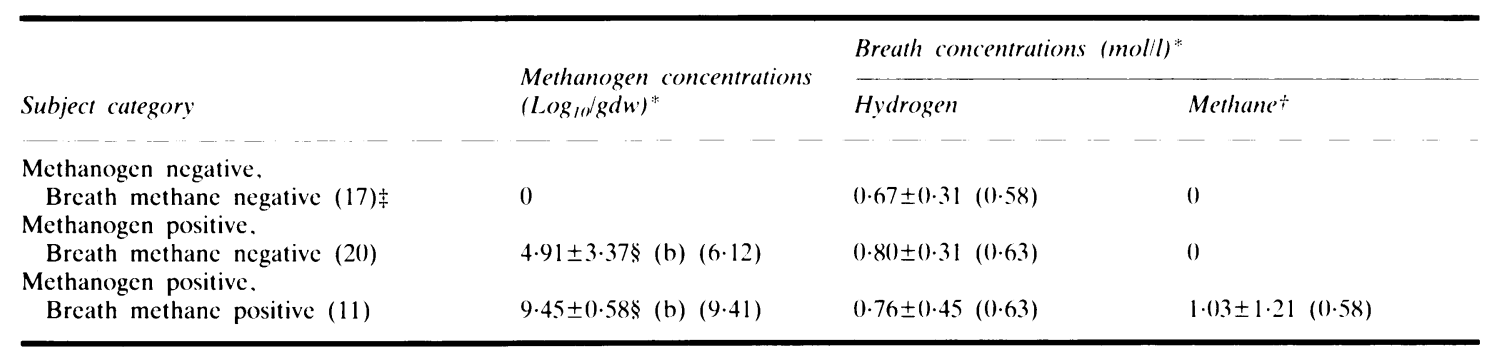

${ }^{*}$ Means \pm standard deviation (median).

$\dagger$ Methane in breath minus the upper ambient methane concentration $(0 \cdot 27 \mu \mathrm{mol} / \mathrm{l})$.

$\ddagger$ (Number of subjects).

$\$$ Means of the $\log _{10}$ concentrations are significantly different by the $t$ test; $p=0.001$.

culosis two. All isolates belonged to the species $M$ smithii.

Forty eight subjects had breath methane determinations. The subject with the lowest concentration of methanogens with detectable breath methane $(>6 \mathrm{ppm})$ had $2 \times 10^{8}$ methanogens/gdw. Eleven of the 48 subjects had detectable breath methane. Using the $t$ test the means of the logs of methanogen concentrations for breath methane positives $\left(\log _{10} 9 \cdot 45 \pm 0 \cdot 58\right)$ and negatives $\left(\log _{10}\right.$ $4.91 \pm 3 \cdot 37$ ) were significantly different with a $p$ value of 0.001 (Table 3 ). A few subjects had exceptionally high concentrations of breath methane in relation to methanogen concentrations and a few had exceptionally low (undetectable) concentrations.

\section{Discussion}

The percentage of methanogen positive individuals in our study is much higher than the $30 \%$ to $61 \%$ of breath methane positive individuals found in normal populations. The lower percentage found in breath methane studies is probably because of the lack of sufficient methane production by low concentrations of methanogens for detection by analysis of breath samples. Approximately $10^{8}$ organisms/gdw are necessary to produce sufficient methane for detection by breath analysis.

The only apparent difference in the distribution of methanogen concentrations was between subjects with diverticulosis and the other colonic classification groups. The predominant methanogen in all groups was $M$ smithii. There was no indication that any of the colonic classifications were related to the establishment of a different species of methanogen in the large bowel. There are a relatively large number of phylogenetically diverse species that can produce methane from hydrogen and carbon dioxide like $M$ smithii, ${ }^{19}$ but none of these other species were detected in any of the subjects.

The higher percentage of diverticulosis subjects with high concentrations of methanogens probably does not represent an aetiological relationship. Some subjects with diverticulosis do not harbour high concentrations of methanogens and some subjects with high concentrations do not have diverticulosis. It is likely that the trend of higher concentrations of methanogens in older patients is related to the increased prevalence of diverticulosis in older patients. A possible explanation for the increased frequency of high concentrations of methanogens in subjects with diverticulosis is that diverticula may provide an especially suitable environment for the growth of methanogens. This could occur by the entrapment of hydrogen gas and preferential conversion to methane as opposed to the loss of hydrogen in flatus. Or, the diverticula may provide a sheltered niche where the slow growing methanogens are not swept away and where symbiotic relationships with hydrogen producing organisms may occur. Most of the methane produced in the large bowel is formed according to the equation:

$$
4 \mathrm{H}_{2}+\mathrm{CO}_{2} \longrightarrow \mathrm{CH}_{4}+2 \mathrm{H}_{2} \mathrm{O}
$$

The results of Bond et al ${ }^{1}$ indicated that methane production occurs primarily in the left colon and that hydrogen is produced primarily in the right colon. Since diverticulosis is primarily a left sided colonic disorder, accumulation of hydrogen in diverticula could lead to increased growth of methanogens in the left colon with increased methanogenesis and decreased loss of hydrogen in flatus. Alternatively, hydrogen produced in the left colon may be rapidly converted to methane, thus making 
it appear that the majority of hydrogen is produced in the right colon.

Methane production in the large bowel is a balance between rates and total amounts of hydrogen formation by non-methanogenic bacteria, rates and total amounts of methane production by methanogenic bacteria and the rate and amount of physical removal of hydrogen in flatus and by absorption into the blood. In the present study, subjects with breath methane always had breath hydrogen, suggesting that the rate of methanogenesis is never sufficient to completely compete with physical removal of hydrogen, or that some hydrogen is produced without methanogens nearby to convert it to methane. This is also supported by reports that ingestion of non-absorbed carbohydrates caused increases in hydrogen production without or with accompanying increases in breath methane. ${ }^{1}{ }^{\circ} 7^{11(-12}$ It has been suggested that methanogen growth and methane production depend mainly on hydrogen produced from endogenous substrates. ${ }^{20}$ Studies of a colostomy patient showed that an anaerobic flora and methanogens can be sustained in the colon in the absence of a normal faecal stream. ${ }^{21}$ Bursts of hydrogen from nonabsorbed carbohydrates may exceed the capacity of the methanogenic biomass to produce methane because the rate of increase in biomass necessary to convert 'exogenous' hydrogen is much slower than the rate of physical removal of hydrogen. The large intestine ecosystem differs from that of the rumen and anaerobic sewage digestors where massive amounts of methane are produced from hydrogen without any significant accumulation of hydrogen. ${ }^{22}$

If it is assumed that the total faeces excreted per day contains the methanogens necessary to produce the amount of methane excreted each day, it is possible to estimate the concentration of methanogens necessary to produce reported daily methane excretion based on the amount of methane produced in association with the growth of methanogens ${ }^{23}$ and the assumption that one cell of $M$ smithii is equivalent to the weight of one Escherichia coli. ${ }^{2+}$ Calculations based on these assumptions suggest that only faecal methanogen concentrations greater than $10^{x}$ methanogens/gdw would produce breath methane concentrations higher than usual ambient concentrations. Similarly, calculations for extremely high methane production $\left(4.51\right.$ Bond et $\left.a l^{1}\right)$ are consistent with $2 \times 10^{11}$ methanogens/gdw.

These calculated ranges for methanogen concentrations are similar to the ranges found in those with detectable breath membrane in our study. Surveys of populations other than those with colon cancer have demonstrated a range of $30 \%$ to $61 \%$ with positive breath methane ${ }^{15-9}$ In the present study, $40 \%$ of all subjects were in the range of $1 \times 10^{7}$ to $3 \times 10^{10}$ methanogens/gdw faeces and $30 \%$ of all subjects but $3 \times 10^{8}$ to $3 \times 10^{10}$ methanogens/gdw.

The percentage of the total population that we examined that harboured some detectable concentration of methanogens was $72 \%$. The lowest concentrations were detected in enrichments that were prepared from $10^{-1}$ dilutions of already dilute enema samples. It is probable that almost all individuals harbour $M$ smithii, albeit some with extremely low concentrations. McKay et al postulated that all healthy subjects may produce methane but only those with sufficient production have detectable breath levels. We speculate that development of high concentrations of methanogens depends on a continuous supply of high concentrations of hydrogen from exogenous or endogenous sources that exceeds the capacity of mechanisms for physically removing hydrogen. The latter processes may be inhibited by physical factors that increase retention of hydrogen in the large bowel such as diverticulosis, colonic motor disorders or tumours and thus lead to high concentrations of breath methane. The fact that resection of the tumour in colon cancer patients led to normal distributions of detectable breath methane concentrations ${ }^{8}$ is consistent with a role for mechanical or physical factors affecting methanogen concentration and increased breath methane concentrations. It should be pointed out that methanogenesis diminishes the pressure that would normally be exerted by a given amount of hydrogen because 4 litres of hydrogen are used to produce 1 litre of methane.

This study was supported in part by the Steven C. Clark Research Fund of The Mary Imogene Bassett Hospital and grant AI20244 from the National Institutes of Health.

The authors also wish to thank E Currenti, E Kusel, M Murdock, C Bordley, J Davis, N Hauser, $\mathrm{D}$ Koffer for technical assistance, and $\mathrm{T}$ Sally for preparation of the manuscript.

\section{References}

1 Bond JH, Engel RF, Levitt MD. Factors influencing pulmonary methane excretion in man. An indirect method of studying the in situ metabolism of the methane-producing colonic bacteria. J Exp Med 1971; 133: $572-88$.

2 Miller TL. Wolin MJ, Conway de Macario E, Macario AJL. Isolation of Methanobrevibacter smithii from human feces. Appl Environ Microbiol 1982; 43: 22732. 
3 Miller TL, Wolin MJ. Enumeration of Methanobrevibacter smithii in human feces. Arch Microbiol 1982; 131: 14-8.

4 Miller TL, Wolin MJ. Stability of Methanobrevibacter smithii populations in the microbial flora excreted from the human large bowel. Appl Environ Microbiol 1983; 45: $317-8$

5 McKay LF, Biol MI, Brydon WG, Eastwood MA, Smith JH. The influence of pentose on breath methane. Am J Clin Nutr 1981; 34: 2728-33.

6 Bjørneklett A, Jenssen E. Relationships between hydrogen $\left(\mathrm{H}_{2}\right)$ and methane $\left(\mathrm{CH}_{4}\right)$ production in man. Scand J Gastroenterol 1982; 17: 985-92.

7 Pitt P, DeBruijn KM, Beeching MF, Goldberg E Blendis LM. Studies on breath methane: the effect of ethnic origins and lactulose. Gut 1980; 21: 951-9.

8 Pique JM, Pallares M, Cuso E, Villaf-Bonet J, Gassull MA. Methane production and colon cancer. Gastroenterology 1984; 84: 601-5.

9 McKay LF, Eastwood MA, Brydon WG. Methane excretion in man - a study of breath, flatus, and faeces. Gut 1985; 26: 69-74.

10 Tadesse K, Eastwood MA. Metabolism of dietary fiber components of man assessed by breath hydrogen and methane. Br J Nutr 1979; 40: 393-6.

11 Beaven J, Bjørneklett A, Jenssen E, Blomhoff JP, Skrede S. Pulmonary hydrogen and methane and plasma ammonia after the administration of lactulose or sorbitol. Scand J Gastroenterol 1983; 18: 343-7.

12 Marthinsen D, Fleming SE. Excretion of breath and flatus gases by humans consuming high-fiber diets. $J$ Nutr 1982; 112: 1133-43.

13 Haines A, Metz G, Dilawari J, Blendis L, Wiggins $H$. Breath-methane in patients with cancer of the large bowel. Lancet 1977; 2: 481-3.
14 Karlin DA, Jones RD, Stroehlein JR, Mastromarino AJ, Potter GD. Breath methane excretion in patients with unresected colorectal cancer. J Natl Cancer Inst 1982; 69: 573-6.

15 Miller TL, Wolin MJ. A serum bottle modification of the Hungate technique for cultivating obligate anaerobes. Appl Microhiol 1974; 27: 986-7.

16 Bryant MP, Burkey LA. Cultural methods and some characteristics of the more numerous groups of bacteria in the bovine rumen. J Dairy Sci 1953; 36: 205-17.

17 Metz G, Gassull MA, Leeds AR, Blendis LM, Jenkins DJA. A simple method of measuring breath hydrogen in carbohydrate malabsorption by endexpiratory sampling. Clin Sci Mol Med 1976; 50; 237-40.

$18 \mathrm{Nia}$ HC, Schoeller DA. Klein PD. Improved gas chromatographic quantitation of breath normalization to respiratory carbon dioxide. J Lab Clin Med 1979; 94: 755-63.

19 Balch WE, Fox GE, Magrum LJ, Woese CR, Wolfe RS. Methanogens: reevaluation of a unique biological group. Microbiol Rev 1979; 43: 260-96.

20 Wolin MJ, Miller TL. Carbohydrate fermentation. In: Hentges DJ, ed. Human intestinal microflora in health and disease. New York: Academic Press, 1983: 147-65.

21 Miller TL, Weaver GA, Wolin MJ. Methanogens and anaerobes in a colon segment isolated from the normal fecal stream. Appl Environ Microbiol 1984; 48: 449-450.

22 Wolin MJ. Fermentation in the rumen and human large intestine. Science 1981; 213: 1463-8.

23 Daniels L, Sparling R, Sprott GD. The bioenergetics of methanogenesis. Biochim Biophys Acta 1984; 768: 113-63.

24 Watson JD. Molecular biology of the gene. New York: WA Benjamin, 1970. 